\title{
Middle East versus Saharan dust extinction-to-backscatter ratios
}

\author{
A. Nisantzi ${ }^{1}$, R. E. Mamouri ${ }^{1}$, A. Ansmann ${ }^{2}$, G. L. Schuster ${ }^{3}$, and D. G. Hadjimitsis ${ }^{1}$ \\ ${ }^{1}$ Cyprus University of Technology, Dep. of Civil Engineering and Geomatics, Limassol, Cyprus \\ ${ }^{2}$ Leibniz Institute for Tropospheric Research, Leipzig, Germany \\ ${ }^{3}$ NASA Langley Research Center, Hampton, Virginia, USA
}

Correspondence to: A. Nisantzi (argyro.nisantzi@cut.ac.cy)

Received: 31 January 2015 - Published in Atmos. Chem. Phys. Discuss.: 24 February 2015

Revised: 01 June 2015 - Accepted: 03 June 2015 - Published: 30 June 2015

\begin{abstract}
Four years (2010-2013) of observations with polarization lidar and sun/sky photometer at the combined European Aerosol Research Lidar Network (EARLINET) and Aerosol Robotic Network (AERONET) site of Limassol $\left(34.7^{\circ} \mathrm{N}, 33^{\circ} \mathrm{E}\right)$, Cyprus, were used to compare extinctionto-backscatter ratios (lidar ratios) for desert dust from Middle East deserts and the Sahara. In an earlier article, we analyzed one case only and found comparably low lidar ratios $<40 \mathrm{sr}$ for Middle East dust. The complex data analysis scheme is presented. The quality of the retrieval is checked within a case study by comparing the results with respective Raman lidar solutions for particle backscatter, extinction, and lidar ratio. The applied combined lidar/photometer retrievals corroborate recent findings regarding the difference between Middle East and Saharan dust lidar ratios. We found values from 43-65 sr with a mean ( \pm standard deviation) of $53 \pm 6 \mathrm{sr}$ for Saharan dust and from 33-48 sr with a mean of $41 \pm 4 \mathrm{sr}$ for Middle East dust for the wavelength of $532 \mathrm{~nm}$. The presented data analysis, however, also demonstrates the difficulties in identifying the optical properties of dust even during outbreak situations in the presence of complex aerosol mixtures of desert dust, marine particles, fire smoke, and anthropogenic haze.
\end{abstract}

\section{Introduction}

The particle extinction-to-backscatter ratio or lidar ratio $S$ is an important quantity in the description of atmospheric aerosols with lidar (Müller et al., 2007; Burton et al., 2012; Groß et al., 2013) and a key input parameter in the retrieval of vertical profiles of the particle extinction coefficient from measurements with elastic backscatter lidars (Fernald, 1984;
Ansmann, 2006) such as the spaceborne Cloud Aerosol Lidar with Orthogonal Polarization (CALIOP) (Omar et al., 2009). Profiles of the particle extinction coefficient throughout the troposphere and stratosphere belong to the basic input data sets in atmospheric modeling of the direct aerosol effect on climate. Dust-related extinction coefficient profiles are also used to estimate ice nuclei concentrations up to cirrus level (Mamouri and Ansmann, 2015). Present and upcoming spaceborne lidar activities (Stoffelen et al., 2005; Ansmann et al., 2007; Winker et al., 2009; Illingworth et al., 2014) need lidar-ratio information for all relevant aerosol types such as urban haze, biomass burning smoke, desert dust and marine particles in key areas of climate relevance for a consistent interpretation of the space-lidar-derived aerosol and cloud products.

Because desert dust is one of the major atmospheric aerosol components and the Sahara and the deserts in the Middle East (Syria, Jordan, Israel, Iraq, Arabian peninsula) are among the major dust sources of the world, the investigation and quantification of the optical properties including the lidar ratio of Saharan and Middle East dust is an important contribution to atmospheric and climate research. Recent Aerosol Robotic Network (AERONET) sunphotometer-based studies of Schuster et al. (2012) and combined observations with polarization lidar and sun/sky photometer by Mamouri et al. (2013) suggest that lidar ratios of Middle East dust are significantly lower (35-45 sr) than the ones for Saharan dust (45-60 sr). The reason seems to be that the illite concentration in dust particles decreases from values around $80 \%$ in western Saharan regions to less than $5 \%$ in the dust particles in eastern Saharan and Middle East desert regions (Schuster et al., 2012). As a consequence the real part of the refractive index decreases from 1.55 for Arabian dust 
to 1.45 for western Saharan dust for the $500-550 \mathrm{~nm}$ wavelength range and the lidar ratio drops from values around $60 \mathrm{sr}$ for western Saharan dust to values around or below $40 \mathrm{sr}$ for Middle East dust.

More studies are needed to corroborate these findings. For this reason we analyzed the full 2010-2013 lidar/photometer data set available for the Limassol station regarding Middle East and Saharan dust outbreaks. Mamouri et al. (2013) demonstrated that a polarization lidar is a basic requirement for a trustworthy retrieval of dust optical properties. The polarization lidar approach allows us to distinguish dust and non-dust contributions to the overall particle optical properties and to extract the dust-related lidar ratio information from the total aerosol backscatter and extinction properties. There is almost no continental site in the Northern Hemisphere which is not affected by omnipresent anthropogenic particles so that lidar-derived extinction-to-backscatter ratios, even when directly determined by means of the Ramanlidar or the High Spectral Resolution Lidar method, are not trustworthy as long as measurements of the depolarization ratio (showing, e.g., values of $>0.3$ in the dust layers at $532 \mathrm{~nm}$ ) are not available. After long-range transport across the oceans, significant mixing with marine particles can never be excluded so that again direct dust lidar-ratio observations need to be interpreted with care when depolarization ratio measurements are missing or show values clearly below 0.3 at $532 \mathrm{~nm}$.

There are already a lot of studies on Saharan dust lidar ratios mostly based on Raman lidar observations (Mattis et al., 2002; Amiridis et al., 2005; Mona et al., 2006; Papayannis et al., 2008; Esselborn et al., 2009; Tesche et al., 2009b, 2011; Groß et al., 2011; Preißler et al., 2013). For heavy dust loads the lidar ratio was typically in the range of 45-60 sr for western Saharan dust sources. Most lidars did not have a polarization sensitive channel for aerosol type separation so that it remains unknown to what extent the retrieval of dust optical properties is biased by the presence of non-dust particles. Respective Raman lidar efforts regarding Middle East dust lidar ratios are not available.

High-quality dust lidar ratio observations with lidar are also required to support respective photometer-based retrievals, because sun photometers do not provide direct observations of $180^{\circ}$ scattering, the lidar ratio cannot be measured and is obtained from modeling. A spheroidal particle shape model is used together with the observed spectral aerosol optical thickness (AOT) and sky radiance measurements to simulate the particle backscatter coefficient and the lidar ratio (Dubovik et al., 2006). The particle shape model assumes that the irregularly shaped dust particles are ideal spheroids. Because column-integrated particle information is measured, lidar ratios for lofted dust layers and the polluted boundary layer (PBL) cannot be distinguished.

The assumption of a spheroidal shape of the dust particles may cause uncertainties in the column dust lidar ratios of the order of $10 \%$ or even more (Müller et al., 2010;
Gasteiger et al., 2011; Wagner et al., 2013). However, Schuster et al. (2012) emphasized the strong influence of the real part of the refractive index on the particle optical properties. The real part dictates the scattering efficiency and has a strong impact on the computation of the extinction and backscatter coefficients. Any fine-mode aerosol contribution to the column aerosol observation was found to decrease the column-integrated real part derived with AERONET and to increase the derived column lidar ratio. Schuster et al. (2012) thus contrasted polluted dust for which the fine-mode volume fraction FVF is $>0.05$ and pure dust scenarios with $\mathrm{FVF}<0.05$.

Another source of uncertainty in AERONET lidar-ratio retrievals arise from the fact that the presence of particles with radius $>15 \mu \mathrm{m}$ is ignored in the complex data analysis which is partly based on inversion methods for which the size spectrum of the particles have to be known a priori. AERONET measurement in the source regions, at heavy dust conditions, or even after long-range transport, but within $30 \mathrm{~h}$ after emission, may be affected by the presence of giant dust particles (Ansmann et al., 2010).

In this article, we summarize our 4 year lidar-ratio observations and present the dust lidar-ratio findings of 17 Middle East and 32 Saharan dust outbreaks. A first lidar-based study of a strong Middle East desert dust outbreak was presented by Mamouri et al. (2013) to highlight the comparably low lidar ratios (34-39 sr) for Arabian dust. The Limassol lidar station at the island of Cyprus in the eastern Mediterranean Sea is unique because it is the only site of the European Aerosol Research Lidar Network (EARLINET) which is influenced by a statistically significant number of dust outbreaks from both the Middle East (5-7 per year) and the Sahara ( $>10$ per year). However, the eastern Mediterranean and the adjacent southwestern Asian and northern African areas are also highly polluted, which strongly complicates the data analysis. As already observed during the United Arab Emirates Unified Aerosol Experiment $\left(\mathrm{UAE}^{2}\right.$ ) campaign (Reid et al., 2008), the Southwest Asian region is one of the most difficult environments in the world regarding characterizing, modeling and monitoring of the atmospheric state. Frequent dust storms, high anthropogenic aerosol levels, and complex air flow pattern dominate the region. This is reflected in our observations, too.

Simultaneous EARLINET lidar and AERONET sun photometer observations were conducted at Limassol almost daily over the 4 year period from May 2010 to December 2013. One of the goals is to cover the overpass times of polar orbiting satellites. Therefore the observations were usually taken between 07:00 and 13:00 UTC (09:00-15:00 local time). Night-time (Raman lidar) observations were only occasionally performed. The data analysis is thus based on the $532 \mathrm{~nm}$ elastic backscatter signals and makes use of the methodology recently introduced by Mamouri et al. (2013).

In Sect. 2, the lidar and sun/sky photometer instruments are briefly described. Section 3 presents the method applied 
to derive dust-related lidar ratios from elastic-backscatter signal profiles. The results are discussed in Sects. 4.1 and 4.2. The reliability of our methodology for the retrieval of dustrelated lidar ratios, outlined in Sect. 3, is checked by means of direct Saharan dust lidar-ratio observation by applying the Raman lidar method (Mattis et al., 2002) during a major Saharan dust storm (Sect. 4.3). In Sect. 5, we compare a limited number of lidar ratio observations with results derived from the AERONET sun photometer measurements alone (Schuster et al., 2012). Summarizing and concluding remarks are presented in Sect. 6.

\section{Instrumentation}

The remote sensing station of the Cyprus University of Technology (CUT) at Limassol $\left(34.7^{\circ} \mathrm{N}, 33^{\circ} \mathrm{E}, 50 \mathrm{~m}\right.$ a.s.l.) is equipped with an EARLINET lidar (Mamouri et al., 2013) and AERONET sun/sky photometer (CUT-TEPAK site, Limassol, Cyprus, http://aeronet.gsfc.nasa.gov) (Holben et al., 1998) and is located about $150 \mathrm{~km}$ south of Turkey and $250 \mathrm{~km}$ west of Syria.

The laser transmits linearly polarized laser pulses at 532 and $1064 \mathrm{~nm}$, and detects the parallel and cross-polarized signal components at $532 \mathrm{~nm}$. Calibration of the polarization channels is performed by rotating the box with the polarization sensitive channels following the methodology of Freudenthaler et al. (2009). Further measurement channels collect lidar return signals at $607 \mathrm{~nm}$ (nitrogen Raman channel) and $1064 \mathrm{~nm}$ (elastic backscatter). The full overlap of the laser beam with the receiver field of view of the $20 \mathrm{~cm}$ Cassegrain telescope is obtained at heights around $300 \mathrm{ma}$ a.s.l. and therefore in most cases within the shallow planetary boundary layer (PBL) reaching up to $350-500 \mathrm{~m}$ height. The basic temporal and spatial signal resolution, with which the raw signals are stored, is $50 \mathrm{~s}$ and $7.5 \mathrm{~m}$, respectively.

The lidar system started performing systematic measurements in May 2010 as a $532 \mathrm{~nm}$ elastic-backscatter lidar. A hardware upgrade was realized in mid-2012 by integrating a $607 \mathrm{~nm}$ Raman channel. In order to provide homogeneous lidar data during the study period (May 2010-December 2013) we used the vertical profiles of the $532 \mathrm{~nm}$ backscatter signals, only. Raman-lidar retrievals are only available at nighttime and only for the EARLINET measurement times (Monday and Thursday evenings). The Raman-lidar observation on 23 May 2013 was used to validate our lidar-ratio approach in the case of a strong Saharan dust outbreak with almost pure dust above $2.5 \mathrm{~km}$ height emitted in the central part of the Saharan desert.

In this paper, we will mainly make use of the determined particle backscatter coefficient and the particle depolarization ratio at $532 \mathrm{~nm}$. The range-corrected signal at $1064 \mathrm{~nm}$ was used only to better illustrate the evolution of dust outbreaks in time-height displays (color plot in Sect. 4.3). The retrieval products are computed from cloud-screened data sets, averaged over almost $1 \mathrm{~h}$ and vertically smoothed with window lengths of $45 \mathrm{~m}$ (up to $2.5 \mathrm{~km}$ height), $60 \mathrm{~m}$ (up to $4 \mathrm{~km}$ height), and $90 \mathrm{~m}$ (above $4 \mathrm{~km}$ height). All data files showing low-level cloud contamination were removed before signal averaging.

Further information of the lidar, the methods applied to analyze the data, the products, and basic retrieval uncertainties can be found in Mamouri et al. (2013) and Mamouri and Ansmann (2014). Details of the determination of the basic volume depolarization ratio profile are given by Nisantzi et al. (2014).

The CUT AERONET sun photometer provides AOT measurements at eight wavelengths from 339 to $1638 \mathrm{~nm}$. It also provides retrievals of column-integrated particle size distributions, complex refractive index, and the number percentage of spherical particles (Dubovik and King, 2000). This is sufficient information to compute the column lidar ratio $S_{\mathrm{A}}$ (Schuster et al., 2012). From the particle size distribution the fine-mode volume fraction FVF is obtained. We further use the Ångström exponent AE (Ångström, 1964), determined from the spectral AOT distribution, and the fine mode fraction FMF (fraction of fine-mode AOT to total AOT) (O'Neill et al., 2003).

During the yearly CIMEL calibration period and/or in case of technical problems, we performed measurements with a MICROTOPS II sun photometer (Solar Light Company, USA) to obtain aerosol optical properties at $440,500,675$, 870 , and $936 \mathrm{~nm}$. To assure high accuracy the sun photometer was mounted on a tripod.

Our study includes a careful investigation of the air mass origin and long-range aerosol transport by means of backward trajectory analysis. The HYSPLIT (HYbrid SingleParticle Lagrangian Integrated Trajectory) model was used for this purpose. Access is provided via the NOAA ARL READY Website (http://www.arl.noaa.gov/HYSPLIT.php). HYSPLIT is described in detail by Draxler and Hess (1997, 1998), and Draxler (1999).

\section{Data analysis procedure}

The data analysis is based on simultaneous observations with polarization lidar and sun/sky photometer (daytime measurements) and follows the procedure outlined in Mamouri et al. (2013). For the correction of Rayleigh backscattering and extinction contributions to the observed signals we calculated the air molecule optical properties by assuming standard atmospheric conditions adjusted to actual surface conditions regarding temperature and pressure. The results in terms of particle backscatter coefficients differ by no more than a few percent (typically by $1 \%$ ) from calculation with temperature and pressure profiles taken from numerical weather prediction model outputs. 
The following data analysis comprises 10 steps. The products include the profiles of the particle backscatter coefficient separately for dust and non-dust aerosol components, the free tropospheric (FT) column dust and non-dust lidar ratios, and dust and non-dust-related particle optical depths of the lofted outbreak plumes. These 10 steps are as follows:

1. We computed the profile of the particle backscatter coefficient with Eq. (2) in Mamouri et al. (2013) with the $532 \mathrm{~nm}$ AOT from the AERONET observations as a constraint. The $532 \mathrm{~nm}$ AOT follows from the measured $500 \mathrm{~nm}$ AOT combined with the $440-675 \mathrm{~nm}$ Ångström exponent. The conventional two-layer Fernald data analysis (Fernald, 1984; Ansmann, 2006; Mamouri et al., 2013) is applied. Layer 1 is the PBL reaching up to 350-500 $\mathrm{m}$ height. Layer 2 extends from the top of the PBL to the top of the lofted FT aerosol layer. By assuming a lidar ratio for the PBL of $S_{\mathrm{PBL}}=$ 25-35 sr, we obtain the particle lidar ratio $S_{\mathrm{T}}$ for the entire tropospheric column and $S_{\mathrm{FT}}$ for the free tropospheric column. The PBL over the coastal city contains a mixture of marine particles showing a lidar ratio of about $20 \mathrm{sr}$ (Groß et al., 2011) and urban haze with lidar ratios of about $50 \mathrm{sr}$ (Müller et al., 2007). $S_{\mathrm{PBL}}$ values around $30 \mathrm{sr}$ are typical for aerosol mixtures of anthropogenic haze and marine particles (Franke et al., 2001). The PBL AOT contribution is usually about $0.02-0.03$, and thus $<10-15 \%$ of the total AOT during dust outbreaks.

2. The particle linear depolarization ratio is calculated from the volume linear depolarization ratio by means of the particle backscatter coefficient profile (Freudenthaler et al., 2009; Tesche et al., 2009b).

3. HYSPLIT backward trajectory analysis together with the profiles of the particle depolarization ratio is used to identify cases with long-range transport of desert dust from the Middle East deserts or from northern Africa (Sahara region). 20-30 Middle East dust outbreaks of different strengths crossed Cyprus during the 4 years understudy. More than 50 cases of Saharan dust longrange transport were identified. For each case, we run the HYSPLIT model with respect to the height of the layers observed over Limassol to identify the source region(s) for the observed aerosol. Observations with passive satellite sensors and estimated PBL heights over the potential source regions were also taken into account in the final decision and identification of contributing aerosol sources.

4. From the total set of dust outbreaks we considered for further analysis (in Sect. 4) only cases in which the particle linear depolarization ratio exceeded 0.15 in the free troposphere and this for a height range of at least $500 \mathrm{~m}$. In this way, we obtained 17 Middle East dust cases and

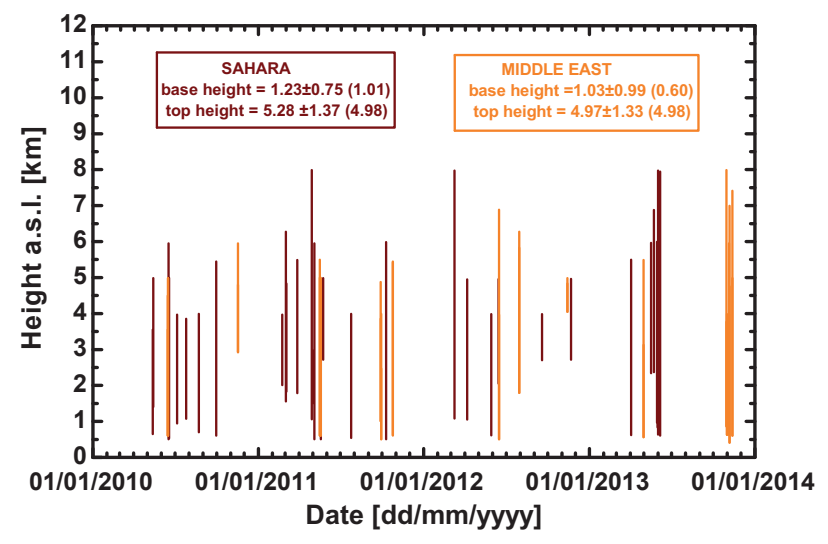

Figure 1. Lofted free-tropospheric desert dust layers (shown as vertical lines from bottom to top) observed between May 2010 and December 2013. The brown and orange vertical lines indicate 32 Saharan dust and 17 Middle East dust cases. The average bottom and top heights (plus the SD) of all detected dust layers are given as numbers. Median values are given in parentheses.

32 Saharan dust cases for our dust lidar-ratio investigations. A comparably low depolarization ratio threshold had to be selected to avoid the omission of too many dust layers. Pure dust layers are rare over Cyprus. Furthermore, fine-mode-dominated dust layers may show a low depolarization ratio close to 0.15 (Mamouri and Ansmann, 2014), but should be included in our data set.

5. In the next step, we calculated the geometrical properties of the remaining dust-containing layers (bottom and top heights). The height range for which the particle linear depolarization ratio is $>0.15$ in the free troposphere represents the FT dust layer. Figure 1 shows base and top heights of all considered dust layers. The base of the FT dust layers frequently coincided with the top of the PBL. The PBL top height was determined from the lidar profiles. The first minimum of the first derivative of the lidar signal normalized to the calculated backscatter signal from atmospheric molecules was taken in most cases as PBL top height (Flamant et al., 1997). However, during dust outbreaks with dust layer base at PBL top, this method did not work. The PBL top was then usually indicated by a clear change in the signal strength as well as in the depolarization ratio. The depolarization ratio was often enhanced in the PBL, compared to a value around $2-3 \%$ as expected for a mixture of marine particles and urban haze. The presence of dust in the PBL does not affect the assumed lidar ratio $S_{\mathrm{PBL}}$ much, because this PBL lidar ratio is still dominated by the marine-urban aerosol mixture. The lidar ratios for urban haze and desert dust are not very different so that the additional presence of desert dust may have increased $S_{\text {PBL }}$ towards 35 sr. We took this into account in the uncertainty analysis below. The top of the dust layers of- 


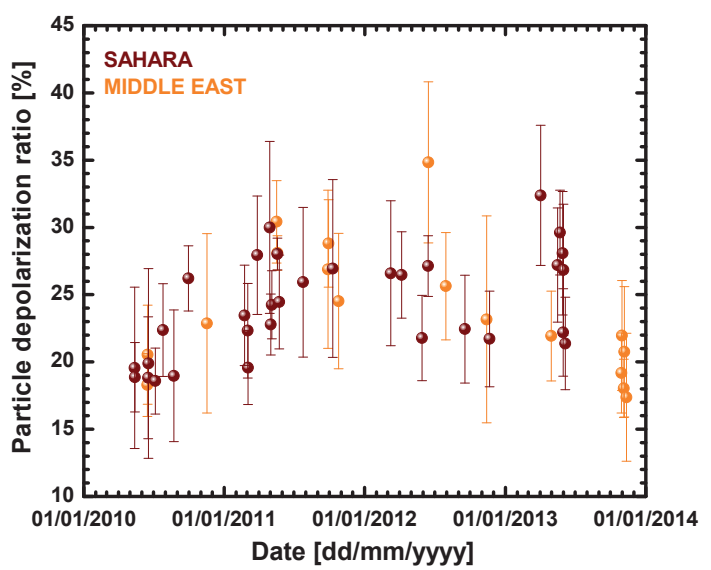

Figure 2. Free-tropospheric dust layer mean particle linear depolarization ratio of all 32 Saharan dust (brown circles) and 17 Middle East dust cases (orange circles). The shown SDs (vertical bars) indicate the vertical variability within each layer in terms of the FT depolarization ratio.

ten reached heights of $4-8 \mathrm{~km}$ a.s.l. This is in agreement with the spaceborne CALIOP lidar study presented by Liu et al. (2008).

6. For each case, the layer-mean linear particle depolarization ratio and the corresponding SD, indicating the variability of the values from base to top within the layer, was computed. Figure 2 provides an overview of the obtained layer-mean particle linear depolarization ratios. In most cases, the mean depolarization ratio was in the range from 0.17 to 0.28 , and indicate aerosol mixtures with dust contributions to particle backscattering of 50 $90 \%$ according to Fig. 1 of Tesche et al. (2011).

7. By using the height profiles of the particle depolarization ratio and the particle backscatter coefficient we determine the dust and non-dust backscatter coefficient profiles (Tesche et al., 2009a) and, based on these profiles, we calculated the FT dust and non-dust column backscatter values (as given in Eq. 4 in Mamouri et al., 2013). In this approach, we assumed a particle linear depolarization ratio of 0.05 for non-dust particles and 0.31 for dust particles so that depolarization ratios $<0.05$ and $>0.31$ indicate a pure non-dust aerosol and a pure dust aerosol, respectively (Freudenthaler et al., 2009; Tesche et al., 2009a; Groß et al., 2011). Mixtures are indicated by depolarization ratios ranging from $0.05-$ 0.31 .

8. In the retrieval of the FT dust lidar ratio $S_{\mathrm{FT}, \mathrm{d}}$ (in the next step 9), we need to assume a FT column lidarratio $S_{\mathrm{FT}, \mathrm{s}}$ for (spherical) non-dust particles. For this, we carefully inspected the backward trajectories. If the air masses only crossed maritime areas before arriving at Limassol, we selected $S_{\mathrm{FT}, \mathrm{s}}$ from 25-30 sr. This is for example the case when dust layers are advected from the Sahara over the polluted Mediterranean Sea to Cyprus in the most direct way. An example is shown in Sect. 4.1 (30 September 2010). If the dust-laden air masses crossed continental (industrialized, urbanized) areas at low heights then we selected 50-55 sr for $S_{\mathrm{FT}, \mathrm{s}}$. Section 4.1 also contains an example for this scenario (17 May 2011). If satellite imagery (Nisantzi et al., 2014) indicated that the air masses crossed regions with biomass burning, we selected $S_{\mathrm{FT}, \mathrm{s}}$ of 65 $70 \mathrm{sr}$ in a few cases. This step of the retrieval introduces a large uncertainty. It was found that the impact of the $S_{\mathrm{FT}, \mathrm{s}}$ assumption is low for FT dust backscatter fractions $D_{\beta}>0.8$, and high for dust backscatter fractions $D_{\beta}$ around 0.5 , which was frequently the case. The FT column dust backscatter fraction $D_{\beta}$ is defined as the ratio of column-integrated dust backscatter coefficient to column-integrated total (dust and non-dust) particle backscatter coefficient for the free troposphere from base height $R_{1}$ to top height $R_{2}$ :

$D_{\beta}=\frac{\int_{R_{1}}^{R_{2}} \beta_{\mathrm{FT}, \mathrm{d}}(z) \mathrm{d} z}{\int_{R_{1}}^{R_{2}} \beta_{\mathrm{FT}}(z) \mathrm{d} z}$.

9. By using the selected $S_{\mathrm{FT}, \mathrm{s}}$ value, we estimated finally $S_{\mathrm{FT}, \mathrm{d}}$, after Eq. (4) in Mamouri et al. (2013). Rearrangement of this equation yields

$S_{\mathrm{FT}, \mathrm{d}}=\frac{S_{\mathrm{FT}}-\left(1-D_{\beta}\right) S_{\mathrm{FT}, \mathrm{s}}}{D_{\beta}}$.

10. Finally we compute (a) the FT aerosol particle optical thickness $\mathrm{AOT}_{\mathrm{FT}}$ from the particle backscatter coefficient profile and the column FT lidar ratio $S_{\mathrm{FT}}$, (b) the FT dust and non-dust particle optical thicknesses $\mathrm{AOT}_{\mathrm{FT}, \mathrm{d}}$ and $\mathrm{AOT}_{\mathrm{FT}, \mathrm{s}}$ from the FT dust and non-dust backscatter coefficient profiles and the respective column lidar ratios $S_{\mathrm{FT}, \mathrm{d}}$ and $S_{\mathrm{FT}, \mathrm{s}}$, and (c) we estimated the dust fraction DF,

$\mathrm{DF}=\frac{\tau_{\mathrm{FT}, \mathrm{d}}}{\tau_{\mathrm{T}}}$

with the free-tropospheric dust AOT $\tau_{\mathrm{FT}, \mathrm{d}}$ and the tropospheric AOT $\tau_{\mathrm{T}}$ as measured with the AERONET sun photometer.

\section{Retrieval uncertainties}

As outlined in Mamouri et al. (2013), the uncertainty in $S_{\mathrm{FT}, \mathrm{d}}$ is almost completely a function of the uncertainties in the assumed PBL lidar ratio $S_{\mathrm{PBL}}$ and the free tropospheric nondust aerosol lidar ratio $S_{\mathrm{FT}, \mathrm{s}}$. By varying each of the two input lidar ratios by $\pm 10 \mathrm{sr}$ (around the assumed values), we estimated the mean uncertainty for each case and each of the two input parameters. In this way, we determined the mean 
uncertainties for both input lidar ratios $S_{\mathrm{PBL}}$ and $S_{\mathrm{FT}, \mathrm{S}}$ for all 49 cases. The uncertainty in $S_{\mathrm{FT}, \mathrm{d}}$ for each case is then calculated from the square root of the quadratic sum of the $S_{\mathrm{PBL}}$ and $S_{\mathrm{FT}, \mathrm{s}}$ error contributions plus a respective uncertainty term resulting from a $10 \%$ uncertainty in the separation of the dust and spherical particle components with the depolarization-ratio technique. These uncertainties are shown as error bars in the last figure of Sect. 4.2. This error computation yields typical uncertainties of $13-19 \%$ in the dust lidar ratios.

In this error analysis, we ignore minor contributions by signal noise, uncertainties in the required Rayleigh extinction and backscatter calculations, and in the particle reference value, which may increase the overall relative uncertainty by a further 5-10\%. We also ignore a minor impact of a few percent by the assumption of the backscatter profile slope in the lowermost $300 \mathrm{~m}$ (region of incomplete laser-beam receiverfield-of-view overlap, see respective particle backscatter profile in several figures of Sect. 4). Here, we used the same assumption (linear decrease of particle backscattering from the surface to $300 \mathrm{~m}$ height by a factor of 2) as in Mamouri et al. (2013).

\section{Results}

We begin the discussion of our 4 year observations with two measurement examples to explain the different steps of the data analysis in detail (Sect. 4.1). An overview of all measurements is then presented in Sect. 4.2. During a few major dust outbreaks, the Raman lidar method (Mattis et al., 2002) could be applied so that desert-dust lidar ratios could directly be determined in the dense dust layers, in which the particle depolarization ratio showed values around 0.3 at $532 \mathrm{~nm}$. In this way, an in-depth evaluation of our entire analysis concept as described in Sect. 3 could be performed. Such a case is discussed in Sect. 4.3.

\subsection{Case studies of 30 September 2010 (Saharan dust) and 17 May 2013 (Middle East dust)}

All observational cases considered in our study were conducted at times from 07:00-13:00 UTC. For all cases sun photometer observations (AERONET or with hand-held MICROTOPS II sun photometer) are available. Figure 3 shows two cases with pronounced dust layers above the PBL. According to the backward trajectories in Fig. 4, a Saharan dust layer and a Middle East desert dust plume were monitored. In both cases, the FT AOT of 0.16 and 0.87 strongly contributed to the total tropospheric AOT of 0.22 and 0.91 , respectively.

In the first step, we obtain the height profile of the particle backscatter coefficient (Mamouri et al., 2013) and the FT lidar ratio $S_{\mathrm{FT}}$. The $532 \mathrm{~nm}$ particle optical depth measured with the sun photometer is used as constraint. A boundarylayer lidar ratio of $30 \mathrm{sr}$ is assumed. It is further assumed that

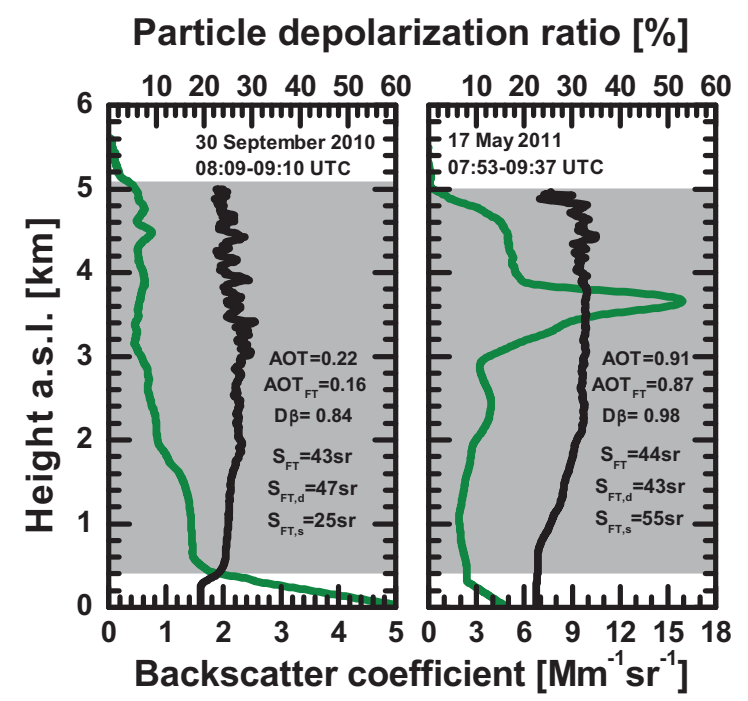

Figure 3. $532 \mathrm{~nm}$ particle backscatter coefficient (green) and particle linear depolarization ratio (black) during a Saharan dust outbreak on 30 September 2010 (left) and a Middle East desert dust outbreak on 17 May 2011 (right). The gray-shaded areas indicate the identified main FT dust layers. Total tropospheric AOT, $\mathrm{AOT}_{\mathrm{FT}}$ for the free troposphere, and several retrieved lidar ratios $\left(S_{\mathrm{FT}}, S_{\mathrm{FT}, \mathrm{d}}\right)$ are given as numbers. The dust fraction was $\mathrm{DF}=0.72$ (30 September) and 0.96 (17 May). Assumed lidar ratios are $S_{\mathrm{PBL}}=30 \mathrm{sr}$ and $S_{\mathrm{FT}, \mathrm{s}}=25 \mathrm{sr}$ (left panel) and $55 \mathrm{sr}$ (right panel). The relative uncertainty in the backscatter coefficient and depolarization ratio is about $10 \%$ (Mamouri et al., 2013).

the backscatter coefficient linearly increases by a factor of 2 from $300 \mathrm{~m}$ above ground down to the surface as mentioned above. In step 2, we determine the particle depolarization ratio, and subsequently, the backscatter contributions by nondust and dust particles (step 7, example is shown in Sect. 4.3 and in Mamouri et al. (2013) and Mamouri and Ansmann (2014)), and the backscatter fraction $D_{\beta}$ (step 8). In step 9, we obtain the FT dust lidar ratio $S_{\mathrm{FT}, \mathrm{d}}$ with Eq. (2). Here, we need to assume the non-dust lidar ratio $S_{\mathrm{FT}, \mathrm{s}}$. We selected $25 \mathrm{sr}$ (Fig. 3 left, assuming a slightly polluted marine aerosol besides desert dust) and $55 \mathrm{sr}$ (Fig. 3 right, assuming mainly anthropogenic particles in the FT aerosol mixture besides the dust). Finally, we are able to estimate all optical depth contributions of the different aerosol components, and the dust fraction DF (step 10).

The dust backscatter fractions of $D_{\beta}=0.84$ and 0.98 indicate that dust clearly dominated the optical properties in the free troposphere. The layer mean particle depolarization ratios were high with values of 0.26 (Saharan dust) and 0.30 (Middle East dust). DF was 0.72 (Saharan dust) and 0.96 (Middle East dust).

Note that even at $4.5-5 \mathrm{~km}$ height dust is detected over Cyprus on 30 September 2010, although the backward trajectory arriving at $4.5 \mathrm{~km}$ height is permanently above $4.5 \mathrm{~km}$ height. This indicates that dust plumes over northern Africa 


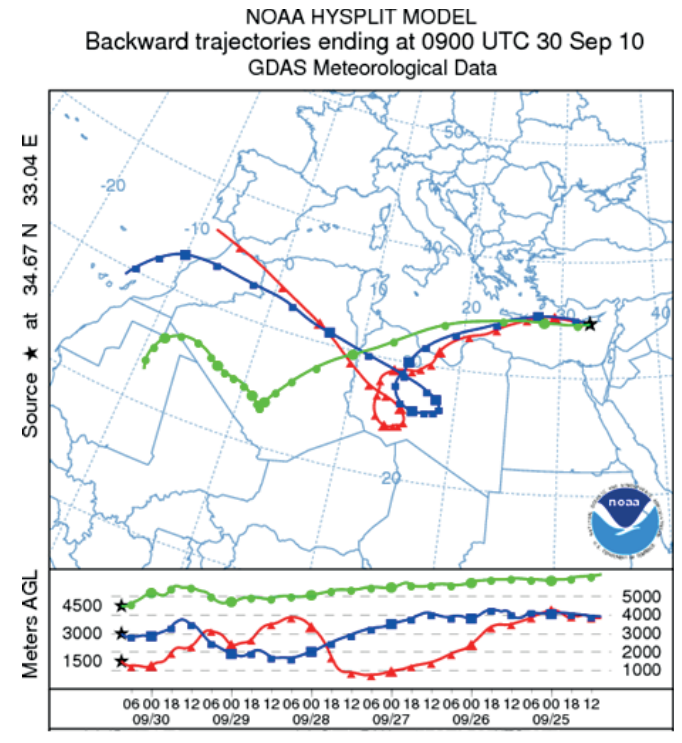

NOAA HYSPLIT MODEL Backward trajectories ending at 0900 UTC 17 May 11 GDAS Meteorological Data

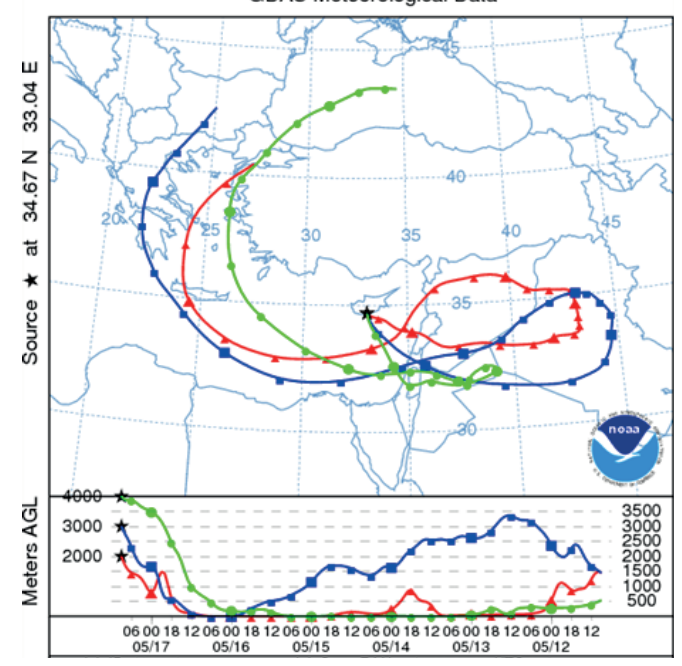

Figure 4. 6-day HYSPLIT backward trajectories arriving at Limassol, Cyprus, at $1500 \mathrm{~m}$ (red, top) and $2000 \mathrm{~m}$ (red, bottom), $3000 \mathrm{~m}$ (blue), $4000 \mathrm{~m}$ (green, bottom), and $4500 \mathrm{~m}$ height (green, top) on 30 September 2010, 09:00 UTC (top) and 17 May 2011, 09:00 UTC (bottom).

typically reach heights of up to 4-6 km above ground during the summer half year (Tesche et al., 2009b). Because all Saharan trajectories indicate a direct air mass transport from the Sahara towards Cyprus (across the polluted Mediterranean Sea) and therefore a very low influence of European haze on the aerosol mixture, we selected a non-dust lidar ratio for free tropospheric aerosols of $S_{\mathrm{FT}, \mathrm{s}}=25 \mathrm{sr}$ which may indicate the impact of marine particles as well as anthropogenic aerosols over northern Africa. The resulting dust lidar ratio $S_{\mathrm{FT}, \mathrm{d}}$ was comparably low with a value of $47 \mathrm{sr}$. However, this value may be representative for the northeastern Saharan region in agreement with the findings of Schuster et al.
(2012) who noticed a steady decrease of the lidar ratio from values of 50-60 sr for western Saharan dust towards 40-45 sr for Middle East dust.

In contrast to the Saharan dust case, a large AOT of 0.91 was observed during a Middle East dust event on 17 May 2011. An almost pure dust plume reached from $500 \mathrm{~m}$ to $5 \mathrm{~km}$ height. According to the backward trajectories (see Fig. 4, lower panel), all air masses which crossed Cyprus between $2-5 \mathrm{~km}$ height were close to the ground over the Middle East region. This explains the high dust load at all heights up to $5 \mathrm{~km}$ in this case. Non-dust aerosol contributions to the observed aerosol mixture were related to European haze, marine particles over the Mediterranean, and anthropogenic aerosols over the southwestern Asian states according to the backward trajectories. As a consequence, we selected an FT non-dust lidar ratio of $S_{\mathrm{FT}, \mathrm{s}}=55 \mathrm{sr}$. However, at these dust-dominating conditions, this estimate (and the related uncertainties) has almost no influence on the result in terms of dust lidar ratio $S_{\mathrm{FT}, \mathrm{d}}$, which was $43 \mathrm{sr}$ and thus close to the values found by Schuster et al. (2012) and Mamouri et al. (2013). Unfortunately we have no AERONET-derived lidar ratio for these two days because of problems with the sun photometer. Only hand-held MICROTOPS sun photometer observations of the AOT could be performed on these days.

\subsection{Statistics: Middle East vs. Saharan dust lidar ratios}

The initial goal of the study was to provide lidar ratios for pronounced desert dust layers with dominant backscattering by mineral dust particles. However, as mentioned above, such conditions are rare. Dust layers mixed with anthropogenic aerosol and marine particles prevail over Cyprus (see Table 1). Almost pure dust layers are observed when $D_{\beta}>0.8$ (see Eq. 1). For these conditions, our retrieval delivers the most reliable results and the relative uncertainty in the dust lidar ratio is low with values down to $10 \%$. In Figs. 5 and 6 overviews of our data analysis for all 17 major Middle East and 32 Saharan dust outbreaks are presented. Figure 5 shows the Middle East dust lidar ratios. For the observed six cases with dust backscatter fractions of $D_{\beta}>0.8$ and corresponding layer mean particle depolarization ratios of $>0.25$ (April 2011 to May 2012), $S_{\mathrm{FT}, \mathrm{d}}$ ranges from $42-46$ sr. For the less dust-dominated 11 cases with $D_{\beta}$ from $0.22-0.7$ most dust lidar ratios were found between $S_{\mathrm{FT}, \mathrm{d}}=35$ and $40 \mathrm{sr}$. Here the uncertainty in the $S_{\mathrm{FT}, \mathrm{d}}$ values introduced by the non-dust lidar ratio assumptions is high (of the order of $10-15 \mathrm{sr}$ ). The mean Middle East dust lidar ratio of all 17 cases is $41.1 \pm 4.3 \mathrm{sr}$.

Figure 6 shows the retrieval results for the Saharan dust outbreaks. For the six cases found with $D_{\beta}>0.8$ we obtain lidar ratios from $47-65 \mathrm{sr}$ with four values in the range from 55-60 sr. We found 14 cases (out of the 32 Saharan dust cases) with layer mean particle depolarization ratios $>0.25$. For these cases, the lidar ratios accumulate in the range from 


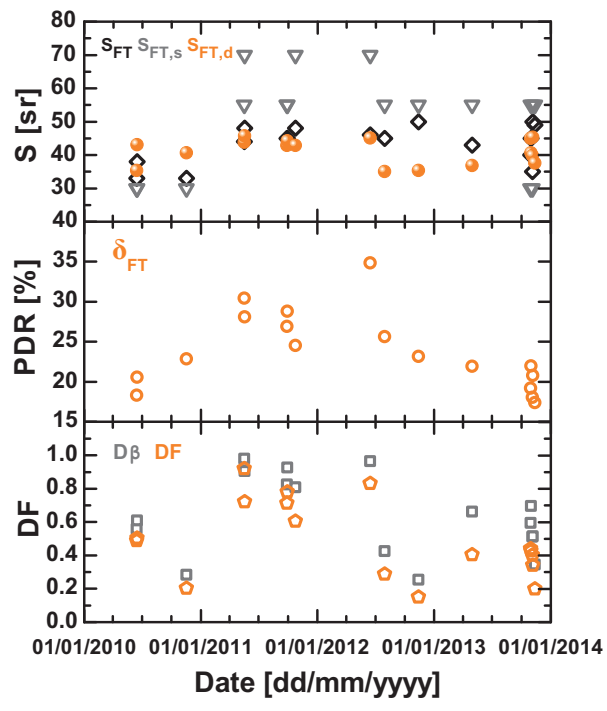

Figure 5. (Top) Retrieved FT $532 \mathrm{~nm}$ lidar ratio $S_{\mathrm{FT}}$ (black diamonds), dust-related lidar ratio $S_{\mathrm{FT}, \mathrm{d}}$ (orange circles), and assumed non-dust lidar ratio $S_{\mathrm{FT}, \mathrm{s}}$ (gray triangles) for 17 Middle East dust outbreaks, (center) mean $532 \mathrm{~nm}$ particle linear depolarization ratio $\delta_{\mathrm{FT}}$ for the FT dust layer, and (bottom) $532 \mathrm{~nm}$ AOT dust fraction DF (orange pentagons, Eq. 3), and FT dust backscatter fraction $D_{\beta}$ (gray squares, Eq. 1).

50-55 sr. In contrast to the Middle East dust events, we assumed low FT non-dust lidar ratios $S_{\mathrm{FT}, \mathrm{s}}$ because the air masses have a comparably long travel distance across the Mediterranean Sea towards Cyprus and the anthropogenic aerosol level over North Africa is lower than over the southwestern Asian region. Most FT dust backscatter fractions $D_{\beta}$ and Saharan DF values were in the range from $0.4-0.8$ and $0.4-0.7$, respectively, which clearly indicates that nondust aerosol types always contributed to the observed particle backscatter and extinction properties. The mean value of the 32 Saharan dust lidar ratios is $52.7 \pm 6.1 \mathrm{sr}$. This lidar ratio is close to the value of $55 \mathrm{sr}$ found by Tesche et al. (2009b) for pure Saharan dust cases.

Figure 7 provides an impression of the uncertainty in the lidar-ratio retrieval. Realistic uncertainties in the most important input parameters are simulated to produce the shown error bars. Although the error bars show uncertainties of the order of 5-12 sr and the corresponding mean SDs (indicated as dashed horizontal lines) in Fig. 7 are large, a difference between the Saharan and Middle East dust lidar ratios is visible. According to the mean values (horizontal solid lines), the Middle East dust lidar ratios are, on average, lower by $12 \mathrm{sr}$ than the Saharan dust lidar ratios.

Table 1 provides additional insight into the aerosol mixing characteristics of the evaluated aerosol scenarios. There were only minor differences between the listed values for Middle East and Saharan dust outbreaks. Comparably high Ångström exponents were measured over Cyprus with the AERONET sun photometer during the dust events. These

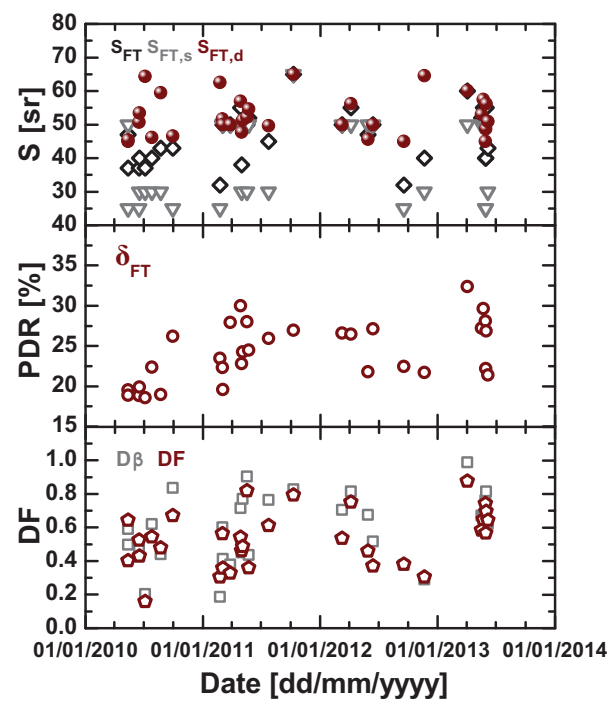

Figure 6. Same as Fig. 5, except for Saharan dust outbreaks.

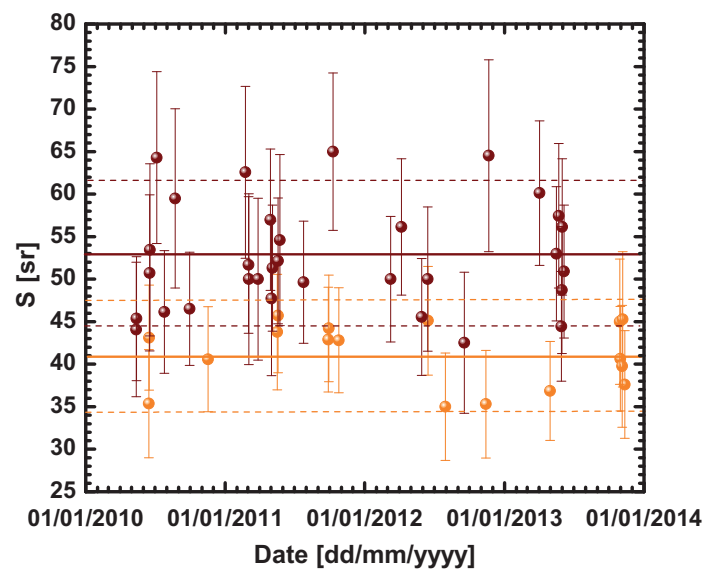

Figure 7. Dust-related lidar ratio $S_{\mathrm{FT}, \mathrm{d}}$ as shown in Fig. 5 (orange, Middle East dust) and Fig. 6 (brown, Saharan dust) with error bars (standard deviation) caused by realistic $\pm 10 \mathrm{sr}$ uncertainties in the lidar-ratio input parameters $S_{\mathrm{PBL}}$ and $S_{\mathrm{FT}, \mathrm{s}}$, and a $10 \%$ uncertainty in the separation of non-dust and dust backscatter coefficient. The solid and dashed (orange and brown) horizontal lines indicate the mean value of the 17 Middle East and 32 Saharan dust lidar ratios and the mean uncertainty (mean error bar length), respectively.

column observations always include the more polluted lowest parts of the atmosphere over the island. Pure dust extinction (and AOT) usually causes an Ånsgtröm exponents of 0.0-0.2 (Tesche et al., 2009b, 2011). Also the fine mode fraction, FMF, is high compared to values of $0.1-0.25$ for strong dust outbreaks (Mamouri and Ansmann, 2014). The dust AOT fraction DF and the dust backscatter fractions $D_{\beta}$ are, on average, much lower than for clearly dust-dominating cases with values of $>0.8$. Table 1 also contains statistics on the derived Saharan and Middle East dust lidar ratios, separately for $D_{\beta}>0.8$ and when considering the full data sets. 
Table 1. Desert dust layer statistics for 49 outbreaks (2010-2013): AERONET Ångström exponent (440-870 nm) and fine-mode fraction (ratio of $500 \mathrm{~nm}$ fine-mode AOT to AOT) for the tropospheric vertical column (T), and lidar-derived $532 \mathrm{~nm}$ dust AOT for the free troposphere (FT), dust fraction DF (Eq. 3), the dust-layer mean particle linear depolarization ratio $(532 \mathrm{~nm})$, the backscatter fraction $D_{\beta}$ (Eq. 1), and the different lidar ratios (for Middle East, M. E., and Saharan dust). Mean value and standard deviation (SD) are given together with the range of observed values (from minimum to maximum value).

\begin{tabular}{lcccc}
\hline Parameter & Mean & SD & Min & Max \\
\hline Ångström exponent (T) & 0.75 & 0.42 & 0.04 & 1.63 \\
Fine-mode fraction (T) & 0.44 & 0.13 & 0.18 & 0.68 \\
Dust AOT (FT) & 0.20 & 0.20 & 0.04 & 1.15 \\
Dust AOT fraction, DF (FT) & 0.64 & 0.21 & 0.18 & 0.99 \\
Depolarization ratio (FT) & 0.24 & 0.04 & 0.17 & 0.35 \\
Backscatt. fraction, $D_{\beta}$ (FT) & 0.62 & 0.22 & 0.19 & 0.99 \\
Lidar ratio (M.E.), $D_{\beta}>0.8$ & 44 & 1 & 43 & 46 \\
Lidar ratio (M.E.) & 41 & 4 & 33 & 48 \\
Lidar ratio (Sah.), $D_{\beta}>0.8$ & 56 & 6 & 47 & 65 \\
Lidar ratio (Sah.) & 53 & 6 & 43 & 65 \\
\hline
\end{tabular}

It is worth to note that values in Table 1 are in agreement with a study by Eck et al. (2008). During the $\mathrm{UAE}^{2}$ campaign, performed in the United Arab Emirates and the adjacent Arabian Gulf region in August-September 2004, they found, on average, Angström exponents of $0.5-0.77$ (440-870 $\mathrm{nm}$ spectrum) for the 14 AERONET stations with slightly higher values for coastal and island sites compared to stations in the center of continental desert regions. Mean $500 \mathrm{~nm}$ FMF values ranged from $0.2-0.8$. These values were mainly caused by strong fine-mode particle sources from petroleum extraction and processing facilities. Only during rather strong dust events (over the desert stations) the Ångström exponent dropped to typical dust values of 0.22 0.31 and the FMF were in the range from $0.24-0.29$. According to Reid et al. (2008) and Eck et al. (2008) it was hard to observe pure dust optical properties, even in desertdominated areas.

\subsection{Case study of 23 May 2013: Raman lidar observation}

We checked the quality of the results obtained with the method described in Sect. 3 for cases where we could include the Raman signals in the aerosol analysis. The Raman lidar technique makes use of both, the elastic backscatter signals at $532 \mathrm{~nm}$ and the nitrogen Raman signals measured at $607 \mathrm{~nm}$ wavelength, and provides height profiles of the particle backscatter and extinction coefficients and thus a direct vertically resolved observation of the desert dust lidar ratio in pronounced dust layers (Mattis et al., 2002), if the depolarization ratio is around 0.3 at $532 \mathrm{~nm}$ which is the case here. In the following, we compare the findings obtained with the

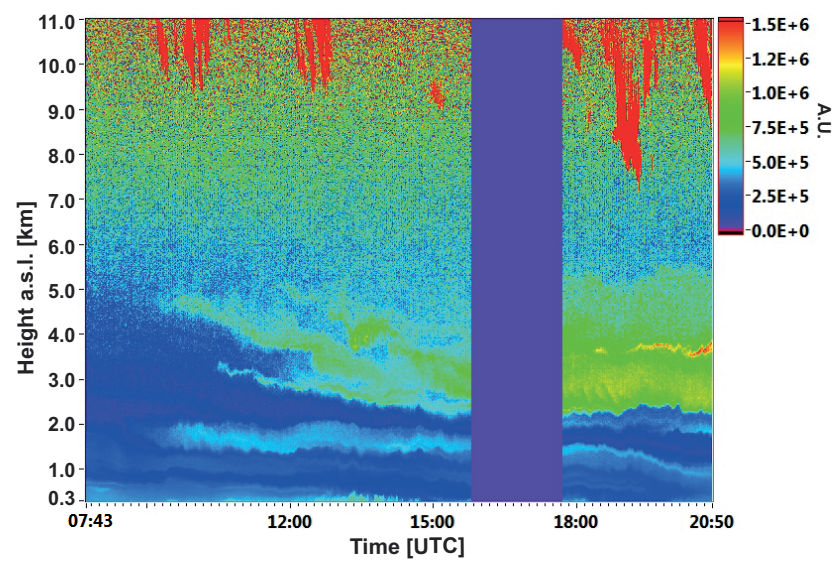

Figure 8. Saharan dust outbreak advecting dust particles between 2 and $6 \mathrm{~km}$ height towards Limassol, Cyprus, on 23 May 2013. Range-corrected $1064 \mathrm{~nm}$ backscatter signals (in arbitrary units, A.U.) are shown. Red features above $7 \mathrm{~km}$ indicate ice clouds.

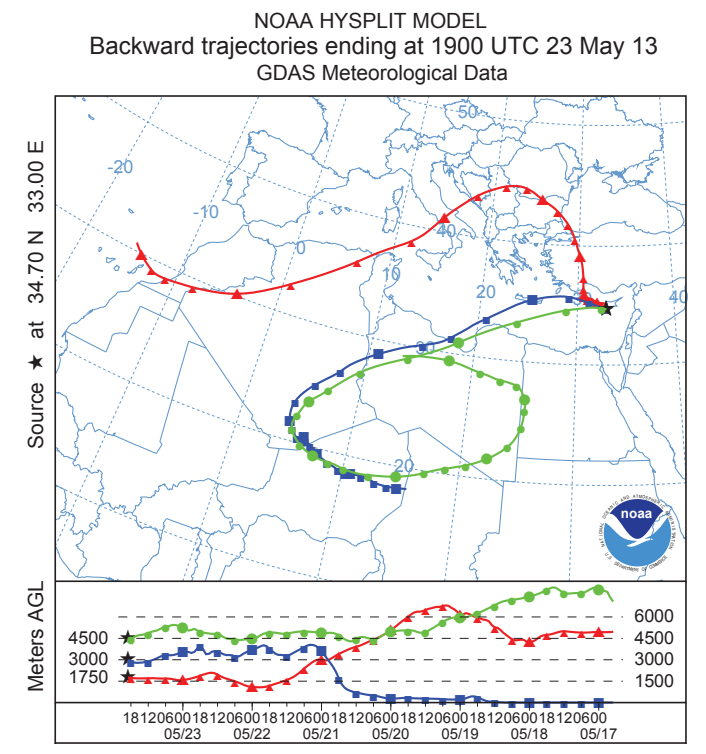

Figure 9. 7-day HYSPLIT backward trajectories arriving at Limassol, Cyprus, at $1750 \mathrm{~m}$ (red), $3000 \mathrm{~m}$ (blue), and $4500 \mathrm{~m}$ height (green) on 23 May 2013, 19:00 UTC.

Raman lidar method and with our approach (Sect. 3) which is based on elastic-backscatter signals only.

Figure 8 shows the arrival of the thick Saharan dust plume over Limassol in the morning of 23 May 2013. According to the backward trajectories arriving above $2 \mathrm{~km}$ height at 19:00 UTC (see Fig. 9), the lofted Saharan dust layer between 2.5 and $5.5 \mathrm{~km}$ height originated from the central parts of the Sahara. Over about 4-5 days, dust could be collected by the air masses before traveling to Cyprus within 1-2 days. The layer below $2 \mathrm{~km}$ height contained a mixture of Saharan dust, European haze, and maritime particles according to the red backward trajectories for the arrival height of $1750 \mathrm{~m}$. 


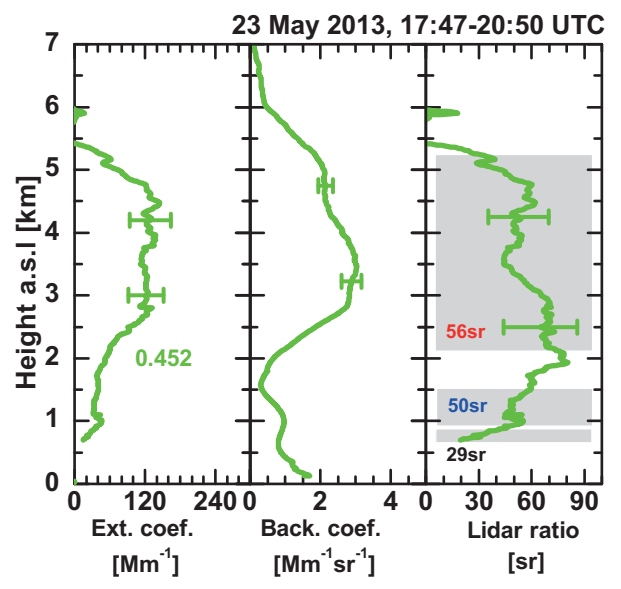

Figure 10. Mean vertical profiles of the $532 \mathrm{~nm}$ particle extinction coefficient, backscatter coefficient, and lidar ratio for the observational period from 17:47-20:50 UTC on 23 May 2013. The Raman lidar method is applied. Vertical signal smoothing lengths of $600 \mathrm{~m}$ (below $1.1 \mathrm{~km}$ height), $1500 \mathrm{~m}$ (1.1-2.8 km height), and $2100 \mathrm{~m}$ (above $2.8 \mathrm{~km}$ height) are applied before computing the extinction coefficients and lidar ratios. The signal smoothing length is $750 \mathrm{~m}$ for the shown backscatter coefficient profile. Total AOT (given as number in the left panel) and layer mean values of the lidar ratio for the $0.7-0.85 \mathrm{~km}$ height layer (influenced by marine and local haze particles), the $0.86-1.5 \mathrm{~km}$ layer (influenced by European haze) and for the pure dust layer (2.1-5.2 km height range) are given as numbers. Error bars provide the uncertainty (standard deviation) by signal noise.

An almost constant aerosol layering was observed above $2000 \mathrm{~m}$ from 17:30-20:50 UTC (see Fig. 8, second observational period after 17:30 UTC). We used this period for a detailed inspection of the optical properties of the Saharan dust plume by applying the Raman lidar method. Figure 10 shows the mean profiles of the $532 \mathrm{~nm}$ particle backscatter and extinction coefficients for the 17:47-20:50 UTC time period, and the respective height profile of the lidar ratio. The $532 \mathrm{~nm}$ dust-related optical depth was close to 0.38 . As can be seen, in agreement with the backward trajectories, the lidar ratio shows typical Saharan dust values between 50-60 sr around the center of the dust layer at $3.5-4.0 \mathrm{~km}$ height. In the layer with European haze between 1.0 and $1.5 \mathrm{~km}$ height, the lidar ratio is close to $50 \mathrm{sr}$, and decreases to values below $30 \mathrm{sr}$ at heights $<1.0 \mathrm{~km}$. As mentioned, values of 25-35 sr are typical for a mixture of anthropogenic and maritime particles (Franke et al., 2001).

In Fig. 11, the products obtained with our retrieval scheme (Sect. 3) are presented. Because after sunset no AERONET data are available, we used the lidar-derived total particle AOT of 0.45 as a constraint in step 1 (see Sect. 3). The AOT was determined from the extinction profile in Fig. 10 (left panel) down to $1 \mathrm{~km}$ height and the backscatter profile below $1 \mathrm{~km}$ multiplied by a lidar ratio of $30 \mathrm{sr}$ for the lowermost $1 \mathrm{~km}$ of the troposphere. The laser-beam RFOV overlap func-

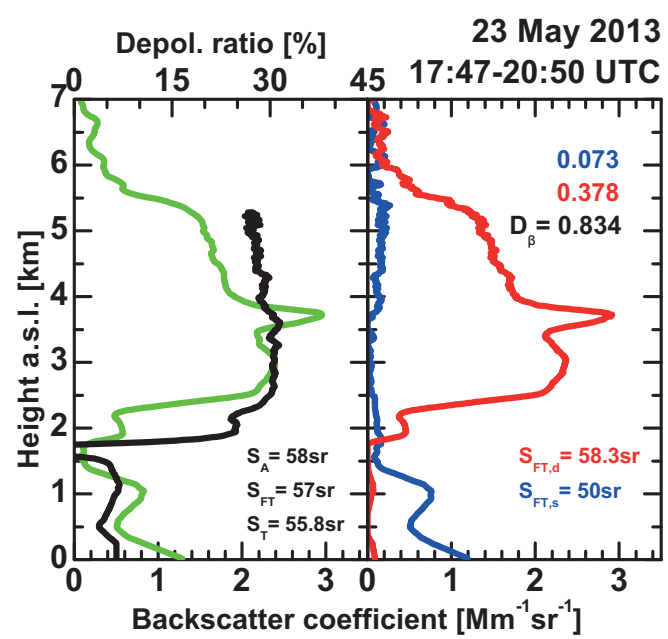

Figure 11. Mean profiles (3-h average) of the $532 \mathrm{~nm}$ particle backscatter coefficient (left, green), particle linear depolarization ratio (left, black), dust backscatter coefficient (right, red), and non-dust particle backscatter coefficient (right, blue). The elasticbackscatter lidar method (explained in Sect. 3) is applied to the same observation as shown in Fig. 10. Retrieved column lidar ratios for the total troposphere $\left(S_{\mathrm{T}}\right)$, the free troposphere $\left(S_{\mathrm{FT}}\right)$, and derived from the AERONET data $\left(S_{\mathrm{A}}\right.$ for the 13:00-14:00 UTC period) for the total tropospheric column after Schuster et al. (2012) are given as numbers in the left panel. $S_{\mathrm{PBL}}$ of $30 \mathrm{sr}$ is assumed for the height range up to $500 \mathrm{~m}$. The retrieved dust-related lidar ratio $S_{\mathrm{FT}, \mathrm{d}}$ and the assumed non-dust lidar ratio $\left(S_{\mathrm{FT}, \mathrm{s}}\right)$ are given in the right panel together with the dust AOT (red number), non-dust AOT (blue number) for the total troposphere, and the FT dust backscatter fractions $D_{\beta}$ (column dust backscatter to total particle backscatter in the free troposphere above $500 \mathrm{~m}$ height). Again, the relative uncertainty in the particle backscatter coefficient and depolarization ratio is $10 \%$, and of the order of $20 \%$ for the dust-related backscatter coefficient (Mamouri et al., 2013).

tion prohibits a trustworthy extinction profiling by means of the Raman-lidar method below about 500-700 m. As a result of step 1, we obtain the column lidar ratio of $S_{\mathrm{FT}}=57 \mathrm{sr}$ for the free troposphere and of $S_{\mathrm{T}}=55.8 \mathrm{sr}$ for the total tropospheric column. This value is close to the AERONET-derived total tropospheric lidar ratio of $S_{\mathrm{A}}=58 \mathrm{sr}$ obtained from the afternoon sun photometer observations (13:00-14:00 UTC). The tropospheric AOT was 0.33 at $500 \mathrm{~nm}$ to that time, measured during periods without cirrus clouds.

In step 2 of the data analysis, the particle linear depolarization ratio shown in Fig. 11 is computed. By means of the profiles of the particle backscatter coefficient and depolarization ratio the profile of the dust backscatter coefficient can then be calculated (step 7, red profile in Fig. 11) so that the column dust backscatter value for the free troposphere and the respective dust fraction $D_{\beta}$ can be calculated (given as number in Fig. 11). The profiles for the particle backscatter coefficient in Figs. 10 and 11 slightly differ because of different methods (Raman-lidar versus Fernald method) used 
in the two figures and the different signal smoothing lengths (750 $\mathrm{m}$ versus $45-90 \mathrm{~m}$ ).

To obtain the dust-related lidar ratio $S_{\mathrm{FT}, \mathrm{d}}$ (steps 8 and 9), we use Eq. (2). Disregarding the clear evidence that we observed a pronounced dust layer above $2 \mathrm{~km}$ on 23 May 2013, we split the troposphere into the PBL (reaching up to $500 \mathrm{~m}$ ) and the free troposphere (from 500-7000 m height). This was generally done for all cases of the 4 year period discussed below. We assumed a PBL lidar ratio of $S_{\mathrm{PBL}}=30 \mathrm{sr}$ and a non-dust lidar ratio $S_{\mathrm{FT}, \mathrm{s}}=50 \mathrm{sr}$ for the free troposphere accounting for the anthropogenic particles mainly confined to the layer from 500-2000 $\mathrm{m}$ height.

The FT column dust backscatter value $D_{\beta}$ of 0.834 in Fig. 11 indicates a dominating dust contribution to the measured optical effects. DF was also 0.83 . The FT column dust lidar ratio $S_{\text {FT,d }}$ was found to be close to $58 \mathrm{sr}$ and thus close to the dust layer mean lidar ratio of $56 \mathrm{sr}$ derived from the Raman lidar observations (see Fig. 10). The influence of uncertainties in the assumed PBL lidar ratio $S_{\mathrm{PBL}}$ on the retrieved dust lidar ratio $S_{\mathrm{FT}, \mathrm{d}}$ is low because the AOT of the PBL is less than $10 \%$ of the total AOT. The uncertainty introduced by an error in the FT non-dust lidar ratio $S_{\mathrm{FT}, \mathrm{s}}$ of $10 \mathrm{sr}$ results in an uncertainty of $<5 \mathrm{sr}$ in the derived $S_{\mathrm{FT}, \mathrm{d}}$ value. Figures 10 and 11 corroborate that our retrieval scheme presented in Sect. 3 allows us to determine dust-related lidar ratios with good accuracy.

\section{Comparison with AERONET observations of dust lidar ratios}

Only a limited number of published lidar-ratio studies is available for comparison. As mentioned in the introduction, most lidar studies did not take the non-dust particle contribution to the observed mixed-aerosol lidar ratios into consideration. Cattrall et al. (2005) and Schuster et al. (2012) extensively discuss Saharan and Middle East dust lidar ratios based on AERONET observations. As also mentioned, these column-integrated measurements include the contribution of PBL aerosols (marine particles, local anthropogenic haze, local road and soil dust) and are frequently affected by long-range transport of non-dust aerosol (fire smoke, lofted marine particles, anthropogenic aerosol).

During events with a strong dust load with AOTs exceeding 0.4, Schuster et al. (2012) found mean values for the desert dust lidar ratio at $532 \mathrm{~nm}$ wavelength of $56.4 \mathrm{sr}$ (over North African AERONET sites), $57.8 \mathrm{sr}$ (Non-Sahel African stations), $55.1 \mathrm{sr}$ (African Sahel sites), and $47.2 \mathrm{sr}$ (AERONET stations in Middle East desert areas) for dustdominated summer months from May to September in the years of 2006 to 2009. During very strong dust events (pure dust cases) with fine-mode volume fraction $\mathrm{FVF}<0.05$ and thus negligible impact of anthropogenic particles on the computations the lidar ratios were on average about $10 \%$ lower.

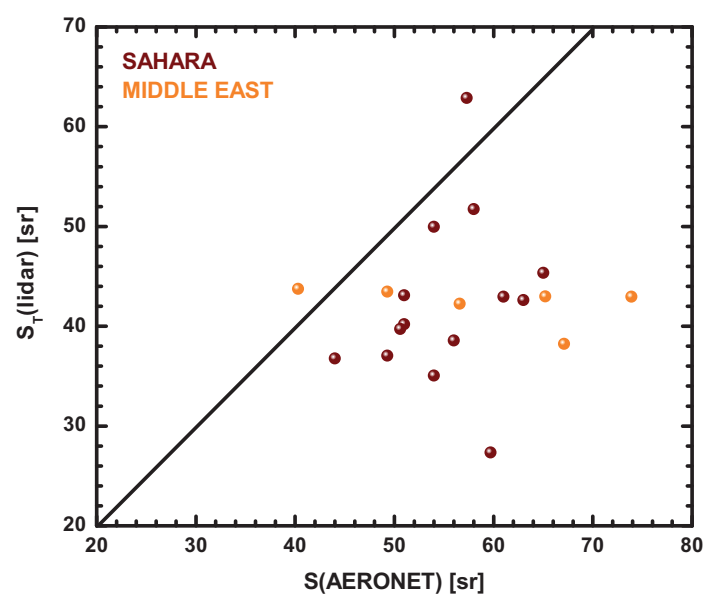

Figure 12. Lidar-derived total tropospheric lidar ratio $S_{\mathrm{T}}$ vs. respective AERONET-derived lidar ratio $S_{\mathrm{A}}$ after Schuster et al. (2012). 14 Saharan dust events and 6 Middle East dust cases, observed over Limassol in the 2010-2013 period, could be analyzed. The solid line shows the $1: 1$ correlation line.

Cattrall et al. (2005) analyzed the main dust periods from 1994 to 2004 over eastern Asian, Middle East, and North African AERONET stations and found mean values of 39$41 \mathrm{sr}$ for several Middle East sites and 35-38 sr for Saharan sites for the wavelength of $550 \mathrm{~nm}$. Cattrall et al. (2005) used an older, less sophisticated AERONET inversion technique which may explain the differences with respect to the results of Schuster et al. (2012).

Figure 12 provides a comparison between lidar-based $\left(S_{\mathrm{T}}\right)$ and AERONET-based $\left(S_{\mathrm{A}}\right)$ retrieval results for the total tropospheric column. Six Middle East dust events and $14 \mathrm{Sa}-$ haran dust cases are available for this comparison. Only this limited number of AERONET data could be analyzed. Most of the data are quality-assured AERONET data (level 2.0). However, the majority of AERONET observations were performed at AOTs clearly below 0.4 so that the uncertainty is high (Dubovik et al., 2000; Schuster et al., 2012). None of the shown cases passed the pure-dust criteria $(\mathrm{FVF}<0.05)$. As mentioned in the introduction, the problem with fine-mode haze is that these particles lower the overall refractive index. The fine mode is more optically efficient than the coarse mode, and increases the lidar ratio when compared to puredust scenarios. The impact of anthropogenic aerosol is less dominant in the case of lidar retrievals (Fernald data analysis) at $532 \mathrm{~nm}$ wavelength. Coarse mode particles widely control the measured optical effects during dust outbreak situations. This is consistent with the results in Fig. 12. The tropospheric column lidar ratios retrieved from the AERONET observations are in most of the selected dust outbreak cases larger than the lidar-derived lidar ratios. If we further keep in mind that the dust lidar ratio $S_{\mathrm{FT}, \mathrm{d}}$ is, on average, $8 \pm 4 \mathrm{sr}$ higher than the tropospheric lidar ratio $S_{\mathrm{T}}$ for the considered $14 \mathrm{Sa}$ haran dust scenes according to the lidar data analysis and 
lower by about $3 \pm 2 \mathrm{sr}$ for the six Middle East dust cases, one may conclude that it is almost impossible to retrieve reliable dust lidar ratios at sites in the Mediterranean region from AERONET observations, or mode general, outside the deserts.

\section{Conclusions}

A study of dust particle lidar ratios for two major desert dust regions and sources for atmospheric dust has been presented. The particle lidar ratio is an important quantity in the description of atmospheric aerosols and aerosol mixtures in the framework of aerosol typing efforts. It is a key input parameter in the retrieval of height profiles of climate relevant particle extinction coefficient, derived from widely used elastic backscatter lidars including the spaceborne lidar CALIOP. Present and upcoming spaceborne lidar activities need lidarratio information for all relevant aerosol types for a consistent interpretation of the space-lidar-derived aerosol and cloud products around the globe.

We found a significant difference with mean values of $53 \pm 6$ and $41 \pm 4$ sr for Saharan and Middle East desert dust, respectively, which is in good agreement with literature values. A recently introduced polarization lidar technique (Mamouri et al., 2013) for the extraction of dust lidar ratio information from elastic-backscatter lidar observations was applied to the 4-year Cyprus data set.

The study corroborates earlier findings that desert dust plumes contain a mixture of desert dust and a variety of other aerosol components (marine particles, fire smoke, anthropogenic haze). Lofted pure desert dust plumes are more the exception than the rule. From this point of view it is a rather difficult effort to select the optimum lidar ratio in the analysis of CALIOP observations over deserts and adjacent regions. The measurement of the particle depolarization ratio is of crucial importance in order to be able to identify and quantify the dust contribution to the aerosol load and more generally for a high-quality aerosol typing.

Acknowledgements. The authors thank the CUT Remote Sensing Laboratory for their support. The work was co-funded by the European Regional Development Fund and the Republic of Cyprus through the Research Promotion Foundation (PENEK/0311/05). The research leading to these results has also received scientific support from the European Union Seventh Framework Programme (FP7/2011-2015) under grant agreement no. 262254 (ACTRIS project). The authors gratefully acknowledge the NOAA Air Resources Laboratory (ARL) for the provision of the HYSPLIT transport and dispersion model as well for the provision of Global Data Assimilation System (GDAS) data used in this publication. We are also grateful to AERONET for high-quality sun/sky photometer measurements.
Edited by: M. Tesche

\section{References}

Amiridis, V., Balis, D. S., Kazadzis, S., Bais, A., Giannakaki, E., Papayannis, A., and Zerefos, C.: Four-year aerosol observations with a Raman lidar at Thessaloniki, Greece, in the framework of European Aerosol Research Lidar Network (EARLINET), J. Geophys. Res., 110, D21203, doi:10.1029/2005JD006190, 2005.

Ångström, A.: The parameters of atmospheric turbidity, Tellus, 16, 64-75, 1964.

Ansmann, A.: Ground-truth aerosol lidar observations: can the Klett solutions obtained from ground and space be equal for the same aerosol case?, Appl. Optics, 45, 3367-3371, 2006.

Ansmann, A., Wandinger, U., Le Rille, O., Lajas, D., and Straume, A. G.: Particle backscatter and extinction profiling with the spaceborne high-spectral-resolution Doppler lidar ALADIN: methodology and simulations, Appl. Optics, 46, 66066626, 2007.

Ansmann, A., Tesche, M., Groß, S., Freudenthaler; V., Seifert, P., Hiebsch, A., Schmidt, J., Wandinger, U., Mattis, I., Müller, D., and Wiegner, M.: The 16 April 2010 major volcanic ash plume over central Europe: EARLINET lidar and AERONET photometer observations at Leipzig and Munich, Germany, Geophys. Res. Lett., 37, L13810, doi:10.1029/2010GL043809, 2010.

Burton, S. P., Ferrare, R. A., Hostetler, C. A., Hair, J. W., Rogers, R. R., Obland, M. D., Butler, C. F., Cook, A. L., Harper, D. B., and Froyd, K. D.: Aerosol classification using airborne High Spectral Resolution Lidar measurements methodology and examples, Atmos. Meas. Tech., 5, 73-98, doi:10.5194/amt-5-73-2012, 2012.

Cattrall, C., Reagan, J., Thome, K., and Dubovik, O.: Variability of aerosol and spectral lidar and backscatter and extinction ratios of key aerosol types derived from selected Aerosol Robotic Network locations, J. Geophys. Res., 110, D10S11, doi:10.1029/2004JD005124, 2005.

Draxler, R. R.: HYSPLIT4 User's Guide, NOAA Tech. Memo. ERL ARL-230, NOAA Air Resources Laboratory, Silver Spring, MD, 1999.

Draxler, R. R. and Hess, G. D.: Description of the HYSPLIT 4 Modeling System, NOAA Tech. Memo. ERL ARL-224, NOAA Air Resources Laboratory, Silver Spring, MD, 1997.

Draxler, R. R. and Hess, G. D.: An overview of the HYSPLIT 4 modeling system of trajectories, dispersion, and deposition, Aust. Meteorol. Mag., 47, 295-308, 1998.

Dubovik, O. and King, M.: A flexible inversion algorithm for retrieval of aerosol optical properties from Sun and sky radiance measurements, J. Geophys. Res., 105, 20673-20696, doi:10.1029/2000JD900282, 2000.

Dubovik, O., Smirnov, A., Holben, B. N., King, M. D., Kaufman, Y. J., Eck, T. F., and Slutsker, I.: Accuracy assessments of aerosol optical properties retrieved from Aerosol Robotic Network (AERONET) Sun and sky radiance measurements, J. Geophys. Res., 105, 9791-9806, doi:10.1029/2000JD900040, 2000.

Dubovik, O., Sinyuk, A., Lapyonok, T., Holben, B. N., Mishchenko, M., Yang, P., Eck, T. F., Voltne, H., Munoz, O., Veihelmann, B., Van der Zande, W., J., Leon, J.-F., Sorokin, M., 
and Slutsker, I.: Application of spheroid models to account for aerosol particle nonsphericity in remote sensing of desert dust, J. Geophys. Res., 111, D11208, doi:10.1029/2005JD006619, 2006.

Eck, T. F., Holben, B. N., Reid, J. S., Sinyuk, A., Dubovik, O., Smirnov, A., Giles, D., O’Neill, N. T., Tsay, S.-C., Ji, Q., Al Mandoos, A., Ramzan Khan, M., Reid, E. A., Schafer, J. S., Sorokine, M., Newcomb, W., and Slutsker, I.: Spatial and temporal variability of column-integrated aerosol optical properties in the southern Arabian Gulf and United Arab Emirates in summer, J. Geophys. Res., 113, D01204, doi:10.1029/2007JD008944, 2008.

Esselborn, M., Wirth, M., Fix, A., Weinzierl, B., Rasp, K., Tesche, M., and Petzold, A.: Spatial distribution and optical properties of Saharan dust observed by airborne high spectral resolution lidar during SAMUM 2006, Tellus B, 61, 131-143, doi:10.1111/j.1600-0889.2008.00394.x, 2009.

Fernald, F. G.: Analysis of atmospheric lidar observations: some comments, Appl. Optics, 23, 652-653, 1984.

Flamant, C., Pelon, J., Flamant, P. H., and Durand, P.: Lidar determination of the entrainment zone thickness at the top of the unstable marine atmospheric boundary-layer, Bound.-Lay. Meteorol., 83, 247-284, 1997.

Franke, K., Ansmann, A., Müller, D., Althausen, D., Wagner, F., and Scheele, R.: One-year observations of particle lidar ratio over the tropical Indian Ocean with Raman lidar, Geophys. Res. Lett., 28, 4559-4562, doi:10.1029/2001GL013671, 2001.

Freudenthaler, V., Esselborn, M., Wiegner, M., Heese, B., Tesche, M., Ansmann, A., Müller, D., Althausen, D., Wirth, M., Fix, A., Ehret, G., Knippertz, P., Toledano, C., Gasteiger, J., Garhammer, M., and Seefeldner, M.: Depolarization ratio profiling at several wavelengths in pure Saharan dust during SAMUM 2006, Tellus B, 61, 16579, doi:10.1111/j.16000889.2008.00396.x, 2009.

Gasteiger, J., Wiegner, M., Groß, S., Freudenthaler, V., Toledano, C., Tesche, M., and Kandler, K.: Modelling lidarrelevant optical properties of complex mineral dust aerosols, Tellus B, 63, 725-741, doi:10.1111/j.1600-0889.2011.00559.x, 2011

Groß, S., Tesche, M., Freudenthaler, V., Toledano, C., Wiegner, M., Ansmann, A., Althausen, D., and Seefeldner, M.: Characterization of Saharan dust, marine aerosols and mixtures of biomassburning aerosols and dust by means of multi-wavelength depolarization and Raman lidar measurements during SAMUM 2, Tellus B, 63, 706724, doi:10.1111/j.1600-0889.2011.00556.x, 2011.

Groß, S., Esselborn, M., Weinzierl, B., Wirth, M., Fix, A., and Petzold, A.: Aerosol classification by airborne high spectral resolution lidar observations, Atmos. Chem. Phys., 13, 2487-2505, doi:10.5194/acp-13-2487-2013, 2013.

Holben, B. N., Eck, T. F., Slutsker, I., Tanré, D., Buis, J. P., Setzer, A., Vermote, E., Reagan, J. A., Kaufman, Y. J., Nakajima, T., Lavenu, F., Jankowiak, I., and Smirnov, A.: AERONET - a federated instrument network and data archive for aerosol characterization, Remote Sens. Environ., 66, 1-16, 1998.

Illingworth, A. J., Barker, H. W., Beljaars, A., Ceccaldi, M., Chepfer, H., Clerbaux, N., Cole, J., Delanoe, J., Domenech, C., Donovan, D. P., Fukuda, S., Hirakata, M., Hogan, R. J., Huenerbein, A., Kollias, P., Kubota, T., Nakajima, T., Nakajima, T. Y., Nishizawa, T., Ohno, Y., Okamoto, H., Oki, R., Sato, K., Satoh, M., Shephard, M., Velazquez Blazquez, A.,
Wandinger, U., Wehr, T., and van Zadelhoff, G.-J.: The Earthcare Satellite: the next step forward in global measurements of clouds, aerosols, precipitation and radiation, B. Am. Meteorol. Soc., doi:10.1175/BAMS-D-12-00227.1, online first, 2014.

Liu, D., Wang, Z., Liu, Z., Winker, D., and Trepte, C.: A height resolved global view of dust aerosols from the first year CALIPSO lidar measurements, J. Geophys. Res., 113, D16214, doi:10.1029/2007JD009776, 2008.

Mamouri, R. E. and Ansmann, A.: Fine and coarse dust separation with polarization lidar, Atmos. Meas. Tech., 7, 3717-3735, doi:10.5194/amt-7-3717-2014, 2014.

Mamouri, R. E., Ansmann, A., Nisantzi, A., Kokkalis, P., Schwarz, A., and Hadjimitsis, D.: Low Arabian dust extinctionto-backscatter ratio, Geophys. Res. Lett., 40, 4762-4766, doi:10.1002/grl.50898, 2013.

Mamouri, R. E. and Ansmann, A.: Estimated desert-dust ice nuclei profiles from polarization lidar: methodology and case studies, Atmos. Chem. Phys., 15, 3463-3477, doi:10.5194/acp-15-34632015, 2015.

Mattis, I., Ansmann, A., Müller, D., Wandinger, U., and Althausen, D.: Dual-wavelength Raman lidar observations of the extinction-to-backscatter ratio of Saharan dust, Geophys. Res. Lett., 29, 1306, doi:10.1029/2002GL014721, 2002.

Mona, L., Amodeo, A., Pandolfi, M., and Pappalardo, G.: Saharan dust intrusions in the Mediterranean area: three years of Raman lidar measurements, J. Geophys. Res., 111, D16203, doi:10.1029/2005JD006569, 2006.

Müller, D., Ansmann, A., Mattis, I., Tesche, M., Wandinger, U., Althausen, D., and Pisani, G.: Aerosol-type-dependent lidar ratios observed with Raman lidar, J. Geophys. Res., 112, D16202, doi:10.1029/2006JD008292, 2007.

Müller, D., Weinzierl, B., Petzold, A., Kandler, K., Ansmann, A., Müller, T., Tesche, M., Freudenthaler, V., Esselborn, M., Heese, B., Althausen, D., Schladitz, A., Otto, S., and Knippertz, P.: Mineral dust observed with AERONET Sun photometer, Raman lidar and in situ instruments during SAMUM 2006: shape-independent particle properties, J. Geophys. Res., 115, D11207, doi:10.1029/2009JD012523, 2010.

Nisantzi, A., Mamouri, R. E., Ansmann, A., and Hadjimitsis, D.: Injection of mineral dust into the free troposphere during fire events observed with polarization lidar at Limassol, Cyprus, Atmos. Chem. Phys., 14, 12155-12165, doi:10.5194/acp-1412155-2014, 2014.

Omar, A. H., Winker, D. M., Kittaka, C., Vaughan, M. A., Liu, Z., Hu, Y., Trepte, C. R., Rogers, R. R., Ferrare, R. A., Lee, K.-P., Kuehn, R. E., and Hostetler, C. A.: The CALIPSO automated aerosol classification and lidar ratio selection algorithm, J. Atmos. Ocean. Tech., 26, 1994-2014, doi:10.1175/2009JTECHA1231.1, 2009.

O’Neill, N. T., Eck, T. F., Smirnov, A., Holben, B. N., and Thulasiraman, S.: Spectral discrimination of coarse and fine mode optical depth, J. Geophys. Res., 108, 4559, doi:10.1029/2002JD002975, 2003.

Papayannis, A., Amiridis, V., Mona, L., Tsaknakis, G., Balis, D., Bösenberg, J., Chaikovski, A., De Tomasi, F., Grigorov, I., Mattis, I., Mitev, V., Müller, D., Nickovic, S., Pérez, C., Pietruczuk, A., Pisani, G., Ravetta, F., Rizi, V., Sicard, M., Trickl, T., Wiegner, M., Gerding, M., Mamouri, R. E., D’Amico, G., and Pappalardo, G.: Systematic lidar ob- 
servations of Saharan dust over Europe in the frame of EARLINET (2000-2002), J. Geophys. Res., 113, D10204, doi:10.1029/2007JD009028, 2008.

Preißler, J., Wagner, F., Guerrero-Rascado, J. L., and Silva, A. M.: Two years of free-tropospheric aerosol layers observed over Portugal by lidar, J. Geophys. Res.-Atmos., 118, 3676-3686, doi:10.1002/jgrd.50350, 2013.

Reid, J. S., Piketh, S. J., Walker, A. L., Burger, R. P., Ross, K. E., Westphal, D. L., Bruintjes, R. T., Holben, B. N., Hsu, C., Jensen, T. L., Kahn, R. A., Kuciauskas, A. P., Al Mandoo, A., Mangoosh, A., Miller, S. D., Porter, J. N., Reid, E. A., and Tsay, S.-C.: An overview of UAE2 flight operations: observations of summertime atmospheric thermodynamic and aerosol profiles of the southern Arabian Gulf, J. Geophys. Res., 113, D14213, doi:10.1029/2007JD009435, 2008.

Schuster, G. L., Vaughan, M., MacDonnell, D., Su, W., Winker, D., Dubovik, O., Lapyonok, T., and Trepte, C.: Comparison of CALIPSO aerosol optical depth retrievals to AERONET measurements, and a climatology for the lidar ratio of dust, Atmos. Chem. Phys., 12, 7431-7452, doi:10.5194/acp-12-7431-2012, 2012.

Stoffelen, A., Pailleux, J., Källén, E., Vaughan, J. M., Isaksen, L., Flamant, P., Wergen, W., Andersson, E., Schyberg, H., Culoma, A., Meynart, R., Endemann, M., and Ingmann, P.: The Atmospheric Dynamics Mission for global wind field measurements, B. Am. Meteorol. Soc., 86, 73-87, 2005.
Tesche, M., Ansmann, A., Müller, D., Althausen, D., Engelmann, R., Freudenthaler, V., and Groß, S.: Vertically resolved separation of dust and smoke over Cape Verde using multiwavelength Raman and polarization lidars during Saharan Mineral Dust Experiment 2008, J. Geophys. Res., 114, D13202, doi:10.1029/2009JD011862, 2009a.

Tesche, M., Ansmann, A., Müller, D., Althausen, D., Mattis, I., Heese, B., Freudenthaler, V., Wiegner, M., Eseelborn, M., Pisani, G., and Knippertz, P.: Vertical profiling of Saharan dust with Raman lidars and airborne HSRL in southern Morocco during SAMUM, Tellus B, 61, 144-164, doi:10.1111/j.16000889.2008.00390.x, 2009b.

Tesche, M., Groß, S., Ansmann, A., Müller, D., Althausen, D., Freudenthaler, V., and Esselborn, M.: Profiling of Saharan dust and biomass-burning smoke with multiwavelength polarization Raman lidar at Cape Verde, Tellus B, 63, 649-676, doi:10.1111/j.1600-0889.2011.00548.x, 2011.

Wagner, J., Ansmann, A., Wandinger, U., Seifert, P., Schwarz, A., Tesche, M., Chaikovsky, A., and Dubovik, O.: Evaluation of the Lidar/Radiometer Inversion Code (LIRIC) to determine microphysical properties of volcanic and desert dust, Atmos. Meas. Tech., 6, 1707-1724, doi:10.5194/amt-6-1707-2013, 2013.

Winker, D. M., Vaughan, M. A., Omar, A., Hu, Y., Powell, K. A., Liu, Z., Hunt, W. H., and Young, S. A.: Overview of the CALIPSO mission and CALIOP data processing algorithms, J. Atmos. Ocean. Tech., 26, 2310-2323, doi:10.1175/2009JTECHA1281.1, 2009. 